\title{
Use of Single-dose Low-level Laser Therapy for Pain Control on Initial Archwire Activation of Orthodontic Appliance: A Randomized Control Clinical Trial
}

\author{
Prasanna T Ramaiah ${ }^{1}$, Tobin Thomas $^{2}$, Srinivasa Hanumanthaiah ${ }^{3}$, Chethan K Dakshina ${ }^{4}$, Jibin K Sabu ${ }^{5}$, Swaroop Subramonia ${ }^{6}$
}

\begin{abstract}
Aim: To compare and evaluate the relative analgesic efficacy of low-level single-dose laser and placebo irradiation after the placement of the first arch wire (0.016 inch Ni-Ti wire) at $6,12,24,36,48$, and 72 hours using a visual analog scale (VAS).

Materials and methods: Fifteen maxillary arches of 15 patients were selected for the study. All the brackets and molar tubes were bonded and 0.016-inch nickel-titanium wire was inserted and ligated to the bracket using 0.009 inch stainless steel wire. After performing the orthodontic procedures, a low-level laser therapy (LLLT) of wavelength of $980 \mathrm{~nm}$ an output of $2 \mathrm{~W}$ with an energy density of $40 \mathrm{~J} / \mathrm{cm}^{2}$ side, and an application dose of $10 \mathrm{~J} / \mathrm{cm}^{2}$ were applied on the buccal and palatal sides of each tooth for 20 seconds, respectively. The laser beam was placed for the control group on the contralateral side for the same extent of time but in the switched off mode. Patients were asked to assess the pain at home at $6,12,24,36,48$, and 72 hours after irradiation using a VAS.

Results: In both the groups, pain increased during the first 12 hours and gradually decreased over the next couple of days. The peak of pain was maximum at 12 hours post irradiation in both the groups. There was a statistically significant $(p<0.005)$ reduction in pain in the experimental group than the control group at all-time intervals.

Conclusion: LLLT significantly reduces orthodontic tooth pain due to the initial archwire activation.

Keywords: Double blind, Initial archwire, LLLT, Randomized control trial, VAS.

World Journal of Dentistry (2019): 10.5005/jp-journals-10015-1634
\end{abstract}

\section{INTRODUCTION}

Orthodontic therapy depends on the reaction of the teeth and more generally the facial structures to gentle but persistent force. When an orthodontic force is applied, tooth movement occurs by remodeling changes in the dental and paradental tissues through the action of chemical mediators. ${ }^{1}$ Orthodontic pain has always been a concern for both clinicians and patients and many patients tend to forego orthodontic treatment due to the pain and discomfort associated with it. ${ }^{2}$ During the course of treatment, pain can be perceived during the placement of separators, archwires, and its activation. Once the archwire is activated, pain starts four hours post activation and will be at its peak within the first 24 hours, and then gradually declines. ${ }^{2-5}$

In order to minimize the symptomatology of pain, various pharmacological, mechanical, and behavioral methods have been adopted by clinicians. Low-level laser therapy (LLLT) is a simple and collateral-free method that is advocated for pain reduction and alleviating inflammation and is rising in popularity among orthodontists due to its noteworthy ability to reduce pain caused by orthodontic appliance placement. ${ }^{6}$ LLLT reduces the prevalence and the intensity of the pain by reducing the secretion of pro-inflammatory molecules such as prostaglandin E2 and interleukin-1 from fibroblast cells. ${ }^{7}$

Although inestimable number of studies has been conducted across the globe over the analgesic effect of LLLT, a standardized dosimetry for pain reduction has not been concluded. The dilemma on the analgesic effect of lasers can be attributed to variation in the dosimetry used, point of laser application, frequency, and interval between irradiation. The techniques used to induce pain also differed among the studies, which supplemented the uncertainty of the effect of LLLT.
${ }^{1-6}$ Department of Orthodontics, Sri Siddhartha Dental College, Sri Siddhartha University of Higher Education, Tumkur, Karnataka, India

Corresponding Author: Tobin Thomas, Department of Orthodontics, Sri Siddhartha Dental College, Sri Siddhartha University of Higher Education, Tumkur, Karnataka, India, Phone: +91 7899292673, e-mail: tobinthomask@gmail.com

How to cite this article: Ramaiah PT, Thomas T, et al. Use of Single-dose Low-level Laser Therapy for Pain Control on Initial Archwire Activation of Orthodontic Appliance: A Randomized Control Clinical Trial. World J Dent 2019;10(3):214-218.

Source of support: Nil

Conflict of interest: None

Therefore, the aim of this study was to assess the analgesic effect of single-dose LLLT after the placement of the first archwire.

\section{Materials and Methods}

The study was conducted in the Department of Orthodontics and Dentofacial Orthopedics, Sri Siddhartha Dental College and Hospital. Ethical clearance (IEC 10/2016) for the study was given by the Institutional Ethics Committee, Sri Siddhartha Dental College and Hospital.

Fifteen patients (nine females and six males) with a mean age of $15.7 \pm 3.035$ years who were planned for orthodontic treatment were selected for the study. Patients who were willing for the study and did not have any systemic illness were included and a written consent was obtained from them. Those patients who were under analgesic medication and those who did not return 
the questionnaires or who reported with debonded brackets were excluded from the study.

Fifteen maxillary arches (nine crowded and six spaced) of 15 patients were randomly assigned with the lottery method to the control and experimental groups. The treatment procedures started between $9 \mathrm{AM}$ and 10.30 AM. All the procedures were conducted following the laser safety protocols.

Once bonding of the brackets and molar tubes were completed, 0.016-inch nickel-titanium (3M Unitek) wire was inserted and ligated to the bracket using 0.009 inch stainless steel wire.

The orthodontic treatment was carried out by a post graduate student under the guidance of an orthodontist. Laser irradiation (MDX diode laser) using a gallium-aluminum-arsenide laser was carried out by an experienced professional. Both the patient and post graduate were blinded in the study. LLLT of a wavelength of $980 \mathrm{~nm}$, an output of $2 \mathrm{~W}$ with an energy density of $40 \mathrm{~J} / \mathrm{cm}^{2}$ side, and an application dose of $10 \mathrm{~J} / \mathrm{cm}^{2}$ were applied on the buccal and palatal sides of each tooth for 20 seconds, respectively (Fig. 1). The laser beam was placed for the control group on the contralateral side for the same extent of time but in the switched-off mode.

Patients were asked to assess the pain at home at 6, 12, 24, 36, 48 , and 72 hours after irradiation using a VAS. They were asked to return the questionnaire after 4 days from the day of laser irradiation.

The student's $t$ test was used to determine whether there was a statistical difference between the groups in the parameters measured.

Student's $t$ test is as follows:

$$
t=\frac{\bar{x}_{1}-\bar{x}_{2}}{s \sqrt{\frac{1}{n_{1}}+\frac{1}{n_{2}}}} \sim t n_{1}+n_{2}-2 \quad \text { where } s_{2}=\frac{\left(n_{1}-1\right) s_{1}{ }^{2}+\left(n_{2}-1\right) s_{2}{ }^{2}}{\left(n_{1}+n_{2}-2\right)}
$$

In the above test, $p$ value less than 0.05 was taken to be statistically significant. The data were analyzed using SPSS package.

\section{Results}

Student's $t$ test was used to compare the mean VAS score between the experimental and control group at different time intervals (Table 1). In both the groups, pain increased during the first 12 hours and gradually decreased over the next couple of days. The peak of pain was maximum at 12 hours post irradiation in both the groups.

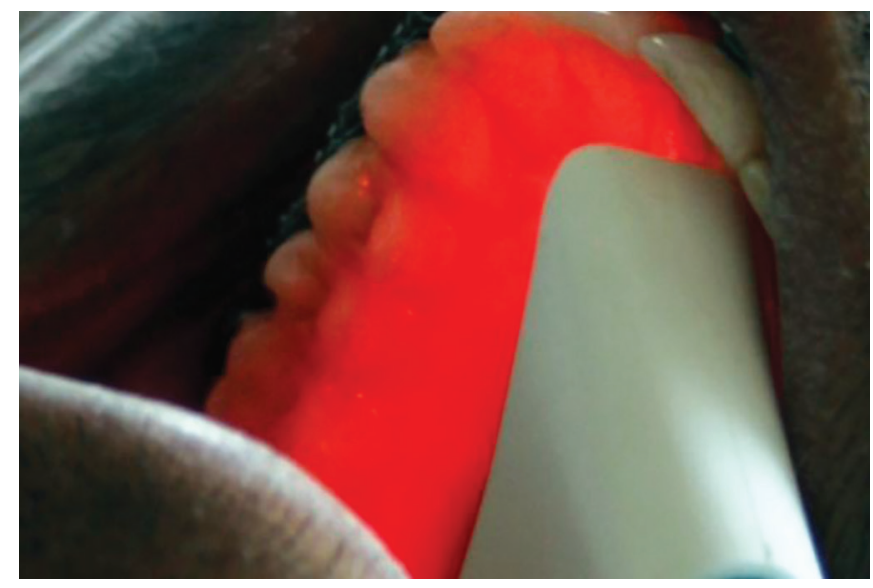

Fig. 1: Laser irradiation for the target tooth
There was a statistically significant $(p<0.005)$ reduction in pain in the experimental group than the control group at all-time intervals.

The mean age of the patients participating in the study was $15.7 \pm 3.035$ years. Among the 15 study population, 9 were females and 6 were males. Nine patients had spaced and six patients had crowded dental arches. No statistically significant difference was obtained when age, sex, and arch length-tooth material discrepancy were considered (Tables 2 and 3). However, clinically pain was expressed more by the female patients than the male patients in the control group.

In both the groups, pain increased during the first 12 hours and gradually decreased over the next couple of days. The peak of pain was maximum at 12 hours post irradiation in both the groups. There was a statistically significant $(p<0.005)$ reduction in pain in the experimental group than the control group at all-time intervals.

On comparison of the mean VAS scores of the male and female patients in the experimental and control groups, there were no statistically significant $(p<0.005)$ results found. Clinically, pain was expressed more by the female patients than the male patients in the control group but no difference was found in the experimental group. Both the male and female patients experienced more pain on the control side than the experimental side.

On comparison of the mean VAS scores of the spacing and crowded arches in the experimental and control groups, there were no statistically significant $(p<0.005)$ results found. However, the pain perception was significantly reduced in the experimental group when compared to the control group.

\section{Discussion}

LLLT has been used as an adjunct to lessen orthodontic pain for the past two decades. It has been advantageous compared to the other methods because its therapeutic window for anti-inflammatory actions overlaps with its ability to improve tissue repair. ${ }^{8}$

The clinical results of LLLT depend on various parameters such as wavelength, energy density, and treatment time. A less than optimal choice can result in reduced effectiveness of the treatment or even a negative therapeutic outcome, as proposed in the Arndt-Schulz law. ${ }^{9}$ Hence, the current study has used the laser parameters within the optimal range and has succeeded in achieving a positive outcome.

LLLT acts via mitochondria displacing nitric oxide from the respiratory chain and thereby increasing the levels of ATP and reactive oxygen species. These changes cause changes in gene expression and subsequent production of chemical messengers. Investigations have shown that LLLT reduces the secretion of highly pro-inflammatory molecules prostaglandin E2 and interleukin-1 from the fibroblast cells that reduced pain after orthodontic tooth movement.

The transmission of light through tissue is highly wavelength specific. LLLT functions in the optimal window of approximately 500 to $1200 \mathrm{~nm}$ wavelength. ${ }^{10}$ The wavelength of the GaAlAs laser used in the current study was $980 \mathrm{~nm}$, which was well within the general acceptable range for LLLT. Turhani et al. ${ }^{11}$ and Tortamano et al. ${ }^{12}$ had used low-level lasers of $670 \mathrm{~nm}$ and $830 \mathrm{~nm}$, respectively, in their studies and were successful in reducing pain after activation of in the initial archwire. According to Hudson et al., ${ }^{13}$ laser of $980 \mathrm{~nm}$ wavelength when applied at close approximation to a tooth root can effectively penetrate to sufficient depth to cause analgesia and the results of this study is in accordance with this finding. On the contrary, study done by Furquim et al. ${ }^{14}$ using elastomeric 
Low Level Laser Therapy for Orthodontic Pain Control

Table 1: Comparison of mean VAS score between the control and experiment groups at different time points

\begin{tabular}{|c|c|c|c|c|c|c|c|c|}
\hline Time & & $n$ & Mean & $S D$ & Min. & Max. & tvalue & $p$ value \\
\hline \multirow[t]{2}{*}{6 hours } & Control & 15 & 6.47 & 1.885 & 0 & 8 & 37.677 & $<0.001$ \\
\hline & Experiment & 15 & 2.60 & 1.549 & 0 & 6 & & \\
\hline \multirow[t]{2}{*}{12 hours } & Control & 15 & 7.20 & 2.242 & 0 & 9 & 34.816 & $<0.001$ \\
\hline & Experiment & 15 & 3.00 & 1.604 & 0 & 7 & & \\
\hline \multirow[t]{2}{*}{24 hours } & Control & 15 & 5.20 & 1.612 & 0 & 7 & 33.501 & $<0.001$ \\
\hline & Experiment & 15 & 1.73 & 1.668 & 0 & 7 & & \\
\hline \multirow[t]{2}{*}{36 hours } & Control & 15 & 3.60 & 1.352 & 0 & 5 & 20.659 & $<0.001$ \\
\hline & Experiment & 15 & 1.40 & 1.298 & 0 & 5 & & \\
\hline \multirow[t]{2}{*}{48 hours } & Control & 15 & 1.67 & 1.397 & 0 & 4 & 8.157 & 0.008 \\
\hline & Experiment & 15 & 0.53 & 0.640 & 0 & 2 & & \\
\hline \multirow[t]{2}{*}{72 hours } & Control & 15 & 0.93 & 1.223 & 0 & 3 & 5.449 & 0.027 \\
\hline & Experiment & 15 & 0.13 & 0.516 & 0 & 2 & & \\
\hline
\end{tabular}

Table 2: Comparison of mean VAS score between male and female patients in the control and experiment groups at different time points

\begin{tabular}{|c|c|c|c|c|c|c|c|c|c|}
\hline Time & Gender & Group & $n$ & Mean & $S D$ & Min. & Max. & tvalue & $p$ value \\
\hline \multirow[t]{4}{*}{6 hours } & Male & Control & 6 & 5.67 & 2.805 & 0 & 7 & 4.945 & 0.050 \\
\hline & & Experiment & 6 & 2.50 & 2.074 & 0 & 6 & & \\
\hline & Female & Control & 9 & 7.00 & 0.707 & 6 & 8 & 84.500 & $<0.001$ \\
\hline & & Experiment & 9 & 2.67 & 1.225 & 0 & 4 & & \\
\hline \multirow[t]{4}{*}{12 hours } & Male & Control & 6 & 6.17 & 3.189 & 0 & 9 & 4.184 & 0.068 \\
\hline & & Experiment & 6 & 2.83 & 2.401 & 0 & 7 & & \\
\hline & Female & Control & 9 & 7.89 & 1.054 & 6 & 9 & 104.169 & $<0.001$ \\
\hline & & Experiment & 9 & 3.11 & 0.928 & 2 & 5 & & \\
\hline \multirow[t]{4}{*}{24 hours } & Male & Control & 6 & 4.50 & 2.258 & 0 & 6 & 2.899 & 0.119 \\
\hline & & Experiment & 6 & 2.17 & 2.483 & 0 & 7 & & \\
\hline & Female & Control & 9 & 5.67 & 0.866 & 5 & 7 & 105.018 & $<0.001$ \\
\hline & & Experiment & 9 & 1.44 & 0.882 & 0 & 2 & & \\
\hline \multirow[t]{4}{*}{36 hours } & Male & Control & 6 & 3.00 & 1.789 & 0 & 5 & 2.015 & 0.186 \\
\hline & & Experiment & 6 & 1.50 & 1.871 & 0 & 5 & & \\
\hline & Female & Control & 9 & 4.00 & 0.866 & 3 & 5 & 42.667 & $<0.001$ \\
\hline & & Experiment & 9 & 1.33 & 0.866 & 0 & 2 & & \\
\hline \multirow[t]{4}{*}{48 hours } & Male & Control & 6 & 1.33 & 1.211 & 0 & 3 & 1.923 & 0.196 \\
\hline & & Experiment & 6 & 0.50 & 0.837 & 0 & 2 & & \\
\hline & Female & Control & 9 & 1.89 & 1.537 & 0 & 4 & 6.063 & 0.026 \\
\hline & & Experiment & 9 & 0.56 & 0.527 & 0 & 1 & & \\
\hline \multirow[t]{4}{*}{72 hours } & Male & Control & 6 & 0.33 & 0.816 & 0 & 2 & $<0.001$ & 1.000 \\
\hline & & Experiment & 6 & 0.33 & 0.816 & 0 & 2 & & \\
\hline & Female & Control & 9 & 1.33 & 1.323 & 0 & 3 & 9.143 & 0.008 \\
\hline & & Experiment & 9 & 0.00 & $<0.001$ & 0 & 0 & & \\
\hline
\end{tabular}

separators for simulating orthodontic pain found that LLLT of $808 \mathrm{~nm}$ had no analgesic effect. The results of the present study, however, showed that LLLT of $980 \mathrm{~nm}$ wavelength has a significant analgesic effect.

The energy density of the present study was $10 \mathrm{~J} / \mathrm{cm}^{2}$ and was within the normal analgesic range $\left(0.45\right.$ to $10 \mathrm{~J} / \mathrm{cm}^{2}$ per treatment point). ${ }^{15}$

Researches show that LLLT is likely to improve the analgesic effect by increasing the frequency of laser irradiation. The studies done by Heravi et al. ${ }^{16}$ and Abtahi et al. ${ }^{17}$ are conflicting to this fact because despite increased frequency of irradiation, LLLT failed in reducing orthodontic pain. The present study shows that single dose exposure at close approximation to the tissue surface gives better analgesic effects than multiple exposures. A possible reason for the multiple exposures in other studies can be attributed to the use of laser probes rather than wide window unit. We had used a wide window unit of $4 \times 1 \mathrm{~cm}$ dimension for laser irradiation (Fig. 2). The advantage of using these units over probes is that it reduces the frequency of exposures due to its increased surface area. It is always recommended to irradiate the target tissue at very close approximation, since it reduces scattering of the laser beam.

Orthodontic pain starts four hours after the insertion of the initial archwire and will peak within 24 hours followed by gradual decline. ${ }^{3}$ In this study, it was observed that pain was perceived at 
Low Level Laser Therapy for Orthodontic Pain Control

Table 3: Comparison of mean VAS score between spacing and crowding in the control and experiment groups at different time points

\begin{tabular}{|c|c|c|c|c|c|c|c|c|c|}
\hline Time & Inference & Group & $n$ & Mean & $S D$ & Min. & Max. & tvalue & pvalue \\
\hline \multirow[t]{4}{*}{6 hours } & Spacing & Control & 6 & 6.83 & 0.753 & 6 & 8 & 64.692 & $<0.001$ \\
\hline & & Experiment & 6 & 2.00 & 1.265 & 0 & 3 & & \\
\hline & Crowding & Control & 9 & 6.22 & 2.386 & 0 & 8 & 11.066 & 0.004 \\
\hline & & Experiment & 9 & 3.00 & 1.658 & 0 & 6 & & \\
\hline \multirow[t]{4}{*}{12 hours } & Spacing & Control & 6 & 6.83 & 0.753 & 6 & 8 & 145.800 & $<0.001$ \\
\hline & & Experiment & 6 & 2.33 & 0.516 & 2 & 3 & & \\
\hline & Crowding & Control & 9 & 7.44 & 2.877 & 0 & 9 & 11.945 & 0.003 \\
\hline & & Experiment & 9 & 3.44 & 1.944 & 0 & 7 & & \\
\hline \multirow[t]{4}{*}{24 hours } & Spacing & Control & 6 & 5.33 & 0.816 & 5 & 7 & 63.776 & $<0.001$ \\
\hline & & Experiment & 6 & 1.17 & 0.983 & 0 & 2 & & \\
\hline & Crowding & Control & 9 & 5.11 & 2.028 & 0 & 7 & 10.160 & 0.006 \\
\hline & & Experiment & 9 & 2.11 & 1.965 & 0 & 7 & & \\
\hline \multirow[t]{4}{*}{36 hours } & Spacing & Control & 6 & 4.00 & 1.265 & 2 & 5 & 29.412 & $<0.001$ \\
\hline & & Experiment & 6 & 0.67 & 0.816 & 0 & 2 & & \\
\hline & Crowding & Control & 9 & 3.33 & 1.414 & 0 & 5 & 4.863 & 0.042 \\
\hline & & Experiment & 9 & 1.89 & 1.364 & 0 & 5 & & \\
\hline \multirow[t]{4}{*}{48 hours } & Spacing & Control & 6 & 1.67 & 1.633 & 0 & 4 & 4.765 & 0.054 \\
\hline & & Experiment & 6 & 0.17 & 0.408 & 0 & 1 & & \\
\hline & Crowding & Control & 9 & 1.67 & 1.323 & 0 & 4 & 3.241 & 0.091 \\
\hline & & Experiment & 9 & 0.78 & 0.667 & 0 & 2 & & \\
\hline \multirow[t]{4}{*}{72 hours } & Spacing & Control & 6 & 0.83 & 1.329 & 0 & 3 & 2.358 & 0.156 \\
\hline & & Experiment & 6 & 0.00 & $<0.001$ & 0 & 0 & & \\
\hline & Crowding & Control & 9 & 1.00 & 1.225 & 0 & 3 & 2.800 & 0.114 \\
\hline & & Experiment & 9 & 0.22 & 0.667 & 0 & 2 & & \\
\hline
\end{tabular}

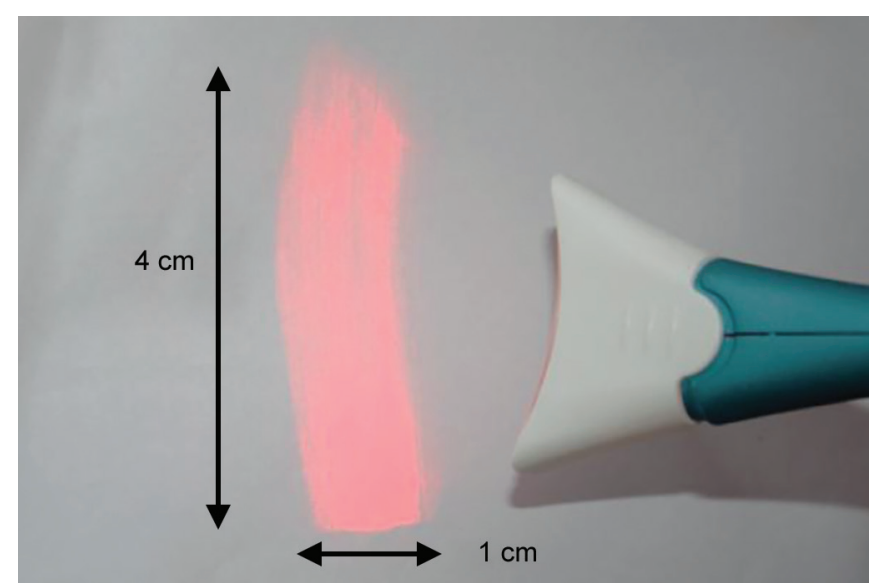

Fig. 2: Wide window photobiomodulation unit

six hours with peak at 12 hours and gradual decline. The onset of pain was similar on the exposed and non-exposed sides though the intensity of pain was significantly lesser on the laser exposed side. Contrary to this observation, Turhani et al. ${ }^{11}$ and Harazaki et al. ${ }^{18}$ observed delay in the onset of pain on the side exposed to laser.

The mean age of the patients selected for this study was 15 years. Among the 15 samples, nine were male and six were females. Nine samples had crowded whereas six had spaced dental arches. The findings of this study showed that age, gender, and incisor irregularity do not affect the pain perceived by the patient. However, this was in contrary to the findings of Tucker et al. ${ }^{19}$ who stated that pain threshold increases rapidly to the age of 25 years after which they are plateaued. Mudrock et al. ${ }^{20}$ in his study indicated that crowded or spaced dental arches do not appear to alter the pain levels experienced by the patients post arch wire activation.

One of the major advantages of this study on comparison with previous studies was blinding of the study. The present study was a double blinded study in which both the clinician and patient were blinded from laser exposure. Patients were not able to differentiate between the experimental and placebo exposure because their eyes were covered using a protective eye wear. Only the laser professional knew the control and experimental sides. This was done to reduce the true-placebo or the Hawthorne effect.

Pain perceived by the patient was recorded via VAS. VAS has been shown to be the most reliable scale for evaluating pain intensity as it is easy to use and evaluate. ${ }^{21}$

Correlating the findings of the current study and comparing them with the previously conducted researches, it can be proposed that LLLT is a superior adjunct to reduce orthodontically induced pain due to the first archwire activation. Further research with a better study design, appropriate sample power, and controlled laser dosimetry is required to provide more reliable evidence for the clinical application of diode LLLT.

\section{Conclusion}

Based on the analysis of the results, conclusions that can be drawn from the current study are as follows:

- The onset of pain was at 6 hours and pain levels peaked at 12 hours after the initial archwire activation and gradually declined in the following days. 
- Age, gender, and arch length-tooth material discrepancy do not have an influence on pain intensity.

- Single dose LLLT application of $980 \mathrm{~nm}$ wavelength, 2 W output power, and $10 \mathrm{~J} / \mathrm{cm}^{2}$ energy density for 40 seconds (20 seconds buccally and 20 seconds palatally) per tooth effectively reduces the intensity of orthodontic pain due to the initial archwire activation.

- Single-dose LLLT application does not alter the onset of orthodontic pain due to the initial archwire activation.

\section{Limitations of the Study}

One of the major disadvantages of this study is the individual perception of pain which is subjective. The second limitation is not standardizing the range of crowding or spacing in the inclusion criteria.

\section{Clinical Significance}

LLLT is painless and least invasive procedure of reducing the orthodontic pain occurs during the course of treatment. Hence, the patients do not have to suffer the immense pain post activation of the appliance.

\section{ACKNOWLedgments}

I would like to thank all my staffs, colleagues, and moreover my family in helping me to complete the study.

\section{References}

1. Krishnan V, Davidovitch ZE. Cellular, molecular, and tissue-level reactions to orthodontic force. Am J Orthod Dentofacial Orthop 2006 Apr 30;129(4):469-e1. DOI: 10.1016/j.ajodo.2005.10.007.

2. Krishnan V. Orthodontic pain: from causes to management-a review. Eur J Orthod 2007 Apr 1;29(2):170-179. DOI: 10.1093/ejo/cjl081.

3. Jones ML. An investigation into initial discomfort caused by placement of arch wire. Eur J Orthod 1984;6:48-54. DOI: 10.1093/ ejo/6.1.48.

4. Jones ML, Chan C. The pain and discomfort experienced during orthodontic treatment: a randomized control clinical trial of two aligning arch wires. Am J Orthod Dentofacial Orthop 1992;102:373381. DOI: 10.1016/0889-5406(92)70054-E.

5. Wilson $\mathrm{S}, \mathrm{Ngan} \mathrm{P}$, et al. Time course of the discomfort in young patients undergoing orthodontic treatment. Pediatr Dent 1989;11:107-109.

6. Elson N, Foran D. Low Level Laser Therapy in Modern Dentistry. Periodon Prosthodon [Internet]. 2015 [cited 2017 Aug 10];1(1):1-4. Available from http://periodontics-prosthodontics.imedpub.com/.

7. Saquib $S$, Jadhav $V$, et al. Low level laser therapy in dentistry: a review. Int J Contemp Dent Med Rev 2014;1:1-3.
8. Fernandes $\mathrm{LM}, \varnothing$ gaard B, et al. Pain and discomfort experienced after placement of a conventional or a superelastic NiTi aligning archwire. J Orofac Orthop 1998 Nov 1;59(6):331-339. DOI: 10.1007/BF01299769.

9. Sobouti $F$, Khatami M, et al. Effect of single-dose low-level heliumneon laser irradiation on orthodontic pain: a split-mouth single-blind placebo-controlled randomized clinical trial. Progress in orthodontics [Internet]. 2015 Sep 29 [cited 2017 Aug 10];16:32. Available from: 10.1186/s40510-015-0102-0.

10. He WL, Li CJ, et al. Efficacy of low-level laser therapy in the management of orthodontic pain: a systematic review and metaanalysis. Lasers Med Sci 2013;28:1581-1589. DOI: 10.1007/s10103-0121196-y.

11. Turhani D, Martina $S$, et al. Pain relief by single low-level laser irradiation in orthodontic patients undergoing fixed appliance therapy. Am J Orthod Dentofacial Orthop 2006;130:371-377. DOI: 10.1016/j.ajodo.2005.04.036.

12. Tortamano A, Lenzi DC, et al. Low-level laser therapy for pain caused by placement of first orthodontic arch wire: A randomized control trial. Am J Orthod Dentofacial Orthop 2009;136:662-667. DOI: 10.1016/j.ajodo.2008.06.028.

13. Hudson DE, Hudson DO, et al. Penetration of laser light at 808 and 980 nm in bovine tissue samples. Photomed Laser Surg 2013;31:163-168. DOI: $10.1089 /$ pho.2012.3284.

14. Furquim RD, Pascotto RC, et al. Low-level laser therapy effects on pain perception related to the use of orthodontic elastomeric separators. Dental Press J Orthod 2015 Jun;20(3):37-42. DOI: 10.1590/21769451.20.3.037-042.oar.

15. He WL, Li CJ, et al. Efficacy of low-level laser therapy in the management of orthodontic pain: a systematic review and metaanalysis. Lasers Med Sci 2013;28:1581-1589. DOI: 10.1007/s10103-0121196-y.

16. Heravi F, Moradi A, et al. The effect of low level laser therapy on the rate of tooth movement and pain perception during canine retraction. Oral Health Dent Manag 2014;13(2):183-188.

17. Abtahi SM, Mousavi SA, et al. Effect of low-level laser therapy on dental pain induced by separator force in orthodontic treatment. Dent Res J 2013;10(5):647-651.

18. Harazaki M, Isshiki Y. Soft laser irradiation effects on pain reduction in orthodontic treatment. Bull Tokyo Dent Coll 1997 Nov;38: 291-295.

19. Tucker MA, Andrew MF, et al. Age associated change in pain threshold measured by transcutaneous neural electrical stimulation. Age Ageing 1989;18:241-246. DOI: 10.1093/ageing/18.4.241.

20. Murdock S, Phillips $C$, et al. Treatment of pain after initial archwire placement: a noninferiorly randomized control clinical trial comparing over-the-counter analgesics and bite wafer use. Am J Orthod Dentofacial Orthop 2010;137:316-323. DOI: 10.1016/j. ajodo.2008.12.021.

21. Chong R, McGrath C, Yang Y. The effectiveness of low level diode laser therapy on orthodontic pain management: a systematic review and meta-analysis. Lasers Med Sci 2015;30:1881-1893. DOI: 10.1007/ s10103-015-1743-4. 